NBER WORKING PAPER SERIES

\title{
COHORT CROWDING: HOW RESOURCES AFFECT COLLEGIATE ATTAINMENT
}

\author{
John Bound \\ Sarah Turner \\ Working Paper 12424 \\ http://www.nber.org/papers/w12424
}

\author{
NATIONAL BUREAU OF ECONOMIC RESEARCH \\ 1050 Massachusetts Avenue \\ Cambridge, MA 02138 \\ August 2006
}

Seminar participants at the NBER Summer Institute, the University of Western Ontario, the University of Michigan, the University of Maryland, the University of California-Berkeley, Syracuse University, Cornell University, and Harvard University (in a much earlier draft) have provided many helpful comments. We are grateful to Michael Baker, Angelo Melino and David Lam for helpful suggestions, to Charlie Brown, Caroline Hoxby, Bill Johnson and Alan Krueger for comments on an earlier draft, to C. Lockwood Reynolds for research assistance, and to N.E. Barr editorial assistance. Partial funding for this research was obtained through the National Bureau of Economic Research, Program on Non-Profits and from the Mellon Foundation. The views expressed herein are those of the author(s) and do not necessarily reflect the views of the National Bureau of Economic Research.

(O2006 by John Bound and Sarah Turner. All rights reserved. Short sections of text, not to exceed two paragraphs, may be quoted without explicit permission provided that full credit, including $\odot$ notice, is given to the source. 
Cohort Crowding: How Resources Affect Collegiate Attainment

John Bound and Sarah Turner

NBER Working Paper No. 12424

August 2006

JEL No. I23, H52

\begin{abstract}
Analyses of college attainment typically focus on factors affecting enrollment demand, including the financial attractiveness of a college education and the availability of financial aid, while implicitly assuming that resources available per student on the supply side of the market are elastically supplied. The higher education market in the United States is dominated by public and non-profit production, and colleges and universities receive considerable subsidies from state, federal, and private sources. Because consumers pay only a fraction of the cost of production, changes in demand are unlikely to be accommodated fully by colleges and universities without commensurate increases in non-tuition revenue. For this reason, public investment in higher education plays a crucial role in determining the degrees produced and the supply of college-educated workers to the labor market. Using data covering the last half of the twentieth century, we find strong evidence that large cohorts within states have relatively low undergraduate degree attainment, reflecting less than perfect elasticity of supply in the higher education market. That large cohorts receive lower public subsidies per student in higher education explains this result, indicating that resources have large effects on degree production. Our results suggest that reduced resources per student following from rising cohort size and lower state expenditures are likely to have significant negative effects on the supply of college-educated workers entering the labor market.
\end{abstract}

John Bound

Department of Economics

University of Michigan

Ann Arbor, MI 48109-1220

and NBER

jbound@umich.edu

Sarah Turner

University of Virginia

Ruffner Hall, Room 294B

405 Emmet Street

Charlottesville, VA 22903-2495

and NBER

sturner@virginia.edu 


\section{Cohort Crowding: How resources affect collegiate attainment}

Analyses of college enrollment and college completion rates typically focus on demand-side factors including the financial attractiveness of a college education and the availability of financial aid. Implicit in this line of research is the assumption that colleges and universities adjust supply fully with changes in demand. However, there is good reason to believe that supply is not even close to perfectly elastic. The higher education market in the United States is dominated by public and non-profit production, and colleges and universities receive considerable subsidies from state, federal, and private sources. Indeed, Winston (1999) estimates that student fees cover only about $12 \%$ percent of total educational costs at public colleges and universities in the U.S. Parallel estimates of the average share of costs covered by student tuition and fees at private colleges and universities are substantially higher, but still less than 50\%, and much lower at the most selective institutions. Because consumers pay only a fraction of the cost of production, changes in demand are unlikely to be accommodated fully by colleges and universities without commensurate increases in non-tuition revenue. For this reason, public investment in higher education plays a crucial role in determining the degrees produced and the supply of college-educated workers to the labor market.

Significant public subsidies for college education brought about the transformation to "mass higher education" in the post World War II decades with the founding of community colleges and dramatic growth in public four-year colleges (Goldin, 1999). Resources for higher education were especially plentiful in the two decades following World War II, a period sometimes referred to as the "Golden Years" of higher education. One study sites an average annual growth rate of $8 \%$ in education 
and general expenditures per student during the decade of the 1960s (Cheit, 1971). The reach of public subsidies during this period extended to capital projects as well as current expenditures, with the number of colleges rising from 1,886 institutions in 1955 to 2,573 in 1970, a rate of almost 1 new institution per week (Finn, 1978). ${ }^{1}$ Fortunes for colleges reversed dramatically at the end of the 1960 s and through the 1970 s, however. The aggregate link between higher education resources and collegiate attainment is unmistakable: the proportion of the population completing a BA rose from about $17 \%$ for those born in 1930, representing college-going in the early 1950s, to about $29 \%$ for those born two decades late in 1950. It would be hard to imagine this dramatic change in attainment without a corresponding increase in public support for higher education. After the 1951 birth cohort, collegiate attainment declined and then stagnated, before rising again with cohorts born in the 1960s.

The link between public funding for higher education and collegiate attainment in the aggregate time series provides circumstantial evidence that changes in collegiate resources per student affect student outcomes. The interpretation of this time series evidence is, however, open to question -- it is possible that expenditures may have been responding to increases in the demand for a college education rather than the other way around. This paper uses variation in the size of the college-age cohorts within states to

\footnotetext{
${ }^{1}$ The period from 1950 to 1970 brought about an enormous expansion in the "capital stock" of the college and university system. Federal and state support were integral in building the physical capital of colleges and universities, in addition to providing subsidies for operating expenses.. For example, the contribution from federal government sources to plant fund accumulation increased from \$12.3 million dollars in 1950 to $\$ 333.7$ million in 1966 , while state funds increased from $\$ 285.2$ million dollars in 1950 to $\$ 738.7$ million in 1966. These data are from Table 129 of the 1972 Digest of Education Statistics, with the Department of Education Surveys “Financial Statistics of Institutions of Higher Education” providing the original source. In addition to the direct grants from the federal government over this interval, the federal government also provided access to substantial (subsidized) loan funds through the Housing Act until 1969.
} 
generate plausibly exogenous variation in the availability of higher education resources per student and to measure the effects on collegiate attainment

Because only part of any observed change in current expenditures is likely to be exogenous and expenditures translate to resources with long lags, direct assessment of the effect of resources per student on degree outcomes using measures of current expenditures or state appropriations is not appropriate. As an alternative, we focus on the effects of "crowding out" brought about by relatively large cohorts within states vying for a limited number of spaces in the higher education sector. Increases in the college-age population shift out the higher education demand function. Yet, in the absence of complete per capita adjustment in educational subsidies, increasing enrollment demand is likely to reduce educational resources per student in aggregate. When an increase in cohort size is not accompanied by a proportionate increase in resources, large cohorts are essentially "crowded out" of the higher education sector. To this end, plausibly exogenous variation in cohort size leads to a test of how the availability of resources at the college and university level affects collegiate attainment.

Within state and year, we find a strong negative association between cohort size and college completion rates. Our preferred estimates suggest that a 10\% increase in the size of the college-age population leads to a $4 \%$ decrease in college completion rates within states. Whether the reductions in college completion rates among large cohorts are caused by declines in the college-preparedness of large cohorts on the demand side of the higher education market or limitations in the adjustment of colleges and universities is important to the understanding of the 'production' of education and the determinants of 
the supply of college-educated workers. ${ }^{2}$ We present compelling evidence that limited adjustment among colleges and universities on the supply-side of the higher education market is the primary cause of the relative reduction in attainment ("crowding out") among large cohorts.

The first section of this analysis sets forth the defining characteristics of the market for higher education in the context of a rudimentary but illustrative model. The high degree of public subsidy, the mixed market of public and non-profit providers, and the differentiated nature of the product in higher education lead to adjustments along both quality and quantity dimensions in response to demand shocks. As a result, the predicted change in undergraduate degree attainment is ultimately less than proportionate to the change in cohort size, which can be thought of as a direct measure of the effect of resources on collegiate attainment. The second section turns to the measurement of variation within states over time in cohort size and the effect of this variable on collegiate attainment. The third section focuses more directly on the nature of adjustments in higher education by type of institution and the link between current revenues available to higher education and cohort size. In the fourth section, we assess the empirical strength of the alternative explanation that larger cohorts may have lower demand for college if college preparedness (e.g., pre-collegiate achievement) is also connected to cohort size; but we find such demand-side factors account for little of the reduction in college completion among large cohorts. The basic finding is that the incomplete adjustment of resources in response to population changes leads to a substantial reduction in collegiate attainment rates.

\footnotetext{
${ }^{2}$ That within-state growth in cohort size is negatively related to collegiate attainment is an established result in the empirical literature (Card and Lemieux (2000) also record this relationship using
} 
The conclusion is clear: resources matter in the production of higher education. Changes in the funding for public colleges and universities have a large impact on both the quantity and the quality of college graduates in the country. Reductions in state appropriations limit the flow of resources to higher education and reduce collegiate attainment, ultimately lowering the long-term supply of college-educated workers in the labor market.

\section{The Market for Higher Education and Responses to Demand Shocks}

\section{Subsidies in the University Marketplace}

The substantial levels of private and public subsidies in the market for higher education have fundamental effects on the "quantity" of collegiate attainment and the "quality" (or resource intensity) of this product. State colleges and universities expanded markedly in the immediate post-war years and are integral to the overall production of college education in the United States. The share of undergraduate degrees awarded by public institutions has increased from about $50 \%$ in 1947 to about $65 \%$ in the $2003-2004$ academic year, while the share of total college enrollment (including enrollment at subbaccalaureate institutions) is even higher at about $79 \%$ in the fall of 2004.

State colleges and universities provide the majority of higher education enrollment opportunities to their residents at a steep discount in price, made possible through substantial public subsidies. Table 1 summarizes the role of state appropriations in the current revenue stream of colleges and universities. Notably, state and local support accounted for $57.5 \%$ of current revenues at the public community colleges and more than $36 \%$ of revenues at comprehensive four-year institutions. Although the share 
of state support (30\%) is somewhat lower at public research universities, the levels tend to be higher, and these institutions also rely on a range of other non-tuition revenues, including resources from private donations and research support from the federal government. Overall, the data in this table show that tuition payments fall far short of covering total educational costs. ${ }^{3}$

As shown in the final columns of Table 1, there are substantial differences in tuition prices between in-state and out-of-state tuition charges ${ }^{4}$ and between private and public institutions. For this reason, public colleges and universities within a potential student's state of residence are the institutions determining the choice set for students likely to be at the margin of college enrollment and completion. Private institutions, particularly the selective colleges and research universities, also rely heavily on nontuition sources of revenue, including donations and income from endowment. Nevertheless, the selective private institutions with substantial subsidies enroll a very small share of the undergraduate population..$^{5}$

Non-tuition revenue affects the tradeoff between enrollment and resources per student faced by colleges and universities and is critical to explaining how these institutions respond to changes in the demand for higher education. We develop a model that applies to a range of colleges and universities, including open-access institutions,

\footnotetext{
${ }^{3}$ Estimates by Winston mentioned earlier place the degree of subsidy even higher because conventional statements of revenues and expenses for colleges and universities fail to account for capital costs (both depreciation and the opportunity cost of funds), which account for an average of $25 \%$ of educational costs.

${ }^{4}$ For 2005-2006, the average ratio of in-state tuition to out-of-state tuition at state flagship universities was .37 , amounting to an average tuition price difference of $\$ 10,558$; in states where there is considerable demand for out-of-state students, differences between in-state and out-of-state undergraduate charges are much larger, with differences of $\$ 19,882$ and $\$ 18,388$ in Colorado and Michigan, respectively for 2005-2006 (Washington State Higher Education Coordinating Board, 2006).

${ }^{5}$ While the state-level is the appropriate unit of analysis for the consideration of the collegiate attainment of students likely to be at the margin of degree attainment, the most competitive level of
} 
flagship universities, and private colleges. Variation among institutions in mission and objectives, as well as resources, produce somewhat different predicted behavioral adjustments by type of institution.

\section{Theoretical Motivation}

On the supply side of the market, colleges and universities combine their own resources with the energies of their students to produce collegiate attainment. University revenues, representing the sum of tuition, fees, and public and private subsidies, are used to purchase inputs like faculty, libraries and dormitories. The essential choices made by the colleges and universities are the number of students to admit and enroll and the level of resources to invest per student, subject to the university's own budget constraint and the level of student demand, which is a function of the quality (or resource intensity) of the education offered. Generating more money either through tuition revenues or subsidies implies having more resources to spend on instruction. When the non-tuition share of revenues does not vary proportionately with the number of students, enrolling more students necessarily implies spreading these resources more thinly. In short, with the presence of non-tuition revenue, colleges and universities face a quality-quantity tradeoff in response to an increase in the number of students wishing to enroll at the prevailing price.

Student demand varies, as usual, with price - the higher the price, ceteris paribus, the lower the share of the population attending college. Demand also varies with the subsidy per student ( $L / n$, where $L$ is the total non-tuition revenue and $n$ is enrollment), as students would clearly prefer to pay a given price to attend an institution with more 
resources devoted to their education. ${ }^{6}$ We introduce the inverse demand function

$T\left(\frac{L}{n}, \frac{n}{\text { pop }}\right)$, which is positive in the first argument and negative in the enrollment rate among college-age students $\left(\frac{n}{p o p}\right) .^{7}$

Much about the behavior of colleges and universities can be inferred from the non-distribution constraint, which applies to both public and private non-profit institutions of higher education and requires that there be no residual shareholders. ${ }^{8}$ Most generally, the nondistribution constraint is: $n T\left(\frac{L}{n}, \frac{n}{p o p}\right)-n c(q)+L=0,{ }^{9}$ where $c(q)$ reflects per-student costs as a function of quality (or resources), with $c^{\prime}(q)>0$ and total costs of $n c(q)$. It follows that the per-student cost of the quality of education provided is simply equal to tuition plus the per-student subsidy $(L / n)$. Although the presentation of tuition revenue as endogenous (determined by the inverse demand function for college enrollment) may capture the circumstances of some private institutions, it is unlikely to

\footnotetext{
${ }^{6}$ Comparison of tuition levels among private institutions makes this point clear. In 2005-2006, Tufts University had tuition and required fee charges of \$32,621 while Harvard University posted tuition and fees of $\$ 32,092$. With an endowment of $\$ 25.4$ billion at Harvard relative to the Tufts endowment of $\$ 845$ million, it should be no surprise that demand revealed by application behavior is greater at Harvard than at Tufts.

${ }^{7}$ This inverse demand curve should be thought of as institution specific. Institution-specific demand is not infinitely elastic with respect to either tuition levels or quality because individual institutions have considerable market power.

${ }^{8}$ This model builds on Hansmann's (1981) effort to illustrate the potential quality-quantity choice for a performing arts organization when private donations depend on the quality of the presentation. Implicitly we are assuming constant returns to scale, which we think of as a reasonable assumption for the long run. Also, we focus only on the choices surrounding undergraduate education, though one might rightly consider other educational outputs such as research or graduate education.

${ }^{9}$ In some states, a component of state funding for higher education depends on enrollment. For simplicity, we have ignored this fact. What is important is the $L$ rises less than proportionately with $n$ and this is always true. The model explains the response of students and college administrations to changes in the size of the college-age population. Additionally, one might imagine that the cost of producing a given level of quality, $c$, would depend not just on the level of quality produced, but also on enrollment rates - as enrollment rates rise, selectivity falls. Letting $c$ be a function of $q$ and $n / p o p$, rather than just $q$, would complicate without changing the basic story.
} 
apply to public colleges and universities where state legislators and governors have considerable sway in the determination of tuition. ${ }^{10}$

The nonlinear constraint showing the tradeoff between enrollment and resources per student provides much of the intuition for analyzing the institutional adjustment to a demand shock. The constraint, illustrated in Figure 1 for the case in which tuition is determined exogenously, is nonlinear and asymptotes at the level of quality equal to tuition, as the number of students enrolled goes to infinity. ${ }^{11}$ At low levels of enrollment, the price of expansion is high as the relative change in per-student resource subsidy is substantial. At higher levels of enrollment (and lower levels of quality), the quantityquality tradeoff is less pronounced as per-student subsidy becomes a tiny piece of the cost of education for any individual student.

Universities face a choice in the production of college education, implicitly weighing a tradeoff between the quantity variable (or the output of the enrollment decision) and the resources spent per student. How colleges and universities weigh this tradeoff depends on their specific "mission" (e.g., the University of Michigan has been given different objectives by the state than Central Michigan University) and their initial levels of endowment or fixed subsidy. We assume that institutions maximize an objective function that includes both quantity $(n)$ and quality $(q)$ components $-U(n, q)$ subject to the constraint $n T-n c(q)+L=0$.

${ }^{10}$ A survey of State Higher Education Executive Officers finds that legislatures in 10 states explicitly set tuition in practice or in statute (Christal, 1997). In other states, tuition determination is generally the responsibility of governing boards or state higher education authorities, with these authorities often composed of political appointees (Kane, Orszag, and Gunter, 2003).

${ }^{11}$ The basic "shape" of the constraint would be the same with the endogenous treatment of tuition though the slope would be steeper and the function would "flatten" at a greater rate. With tuition fixed, the slope of the constraint is $-L / n^{2}$, while endogenous tuition yields $\frac{\partial c(q)}{\partial n}=\frac{-L}{n^{2}} T_{1}+\frac{1}{p o p} T_{2}-\frac{L}{n^{2}}$. 
There is no reason to believe that the objective function is the same across all universities or that all universities and colleges have access to generous non-tuition revenues. Some institutional leaders may have ambitions to upgrade quality while others may find rewards (or requirements from the state) in maximizing enrollment. How quality and enrollment adjust to changes in demand, driven by population variation or by changes in subsidy, brought about by state fiscal shocks will depend on the objective function governing the behavior of the university and the level of subsidy available to the university. At one extreme, potentially representative of the public research universities, institutions weigh the tradeoff between quantity and quality directly and choose to operate at the tangency between the institutional indifference curve and the nondistribution constraint (illustrated in the top panel of Figure 1). In such a situation, enrollment may be independent of student demand (with the demand function crossing the constraint at or to the right of the tangency). Shifts in demand do not change the optimal enrollment-quality choice of the institution, but rather lead to or exacerbate the condition of excess demand.

In the alternative case where institutions simply maximize enrollment, the level of enrollment (and the quality of the collegiate experience) is determined at the intersection of the demand function and the constraint in quality-enrollment space. Without compensating increases in subsidy $(L)$, which would shift out the constraint, the shift in demand occurs along a function with declining resources per student, leading to a less than proportionate increase in enrollment demand. This is illustrated in Figure 1 (bottom panel); along the downward sloping part of the constraint, the change in enrollment will be less than the shift in demand. What is more, quality (resources per student) declines as 
quantity (enrollment) increases along the constraint. Note that, in addition to the decline in enrollment, this decline in resources per student will have a negative effect on collegiate attainment so long as resources are an input in the collegiate production process.

The implication of the model is clear: unless resources increase to match changes in demand, increases in cohort size are likely to lead to lower proportional levels of college enrollment and completion. Increases in cohort size will lead to reductions in the share of the cohort receiving BA (undergraduate) degrees because colleges and universities must trade resources per student, which include substantial subsidies, for larger enrollments. The extent to which institutions respond to changes in cohort size with adjustments in resources per student, tuition price, and enrollment will depend significantly on the mission and control of the college and university. In this section, we highlight the circumstances of public institutions because they enroll the largest share of higher education students and are central to the market; yet, for reasons given, the basic insights apply more broadly to all non-profit colleges and universities.

While the magnitude of the response to an increase in cohort size in terms of collegiate output - measured by degrees awarded - will vary with institutional circumstance, the model predicts $\frac{\partial \ln B A}{\partial \ln P o p}<1$ at the state level in the presence of nontuition revenues that are invariant to cohort size. The strength of this effect will depend on where the institution begins on the budget constraint (e.g., on the steep portion where the quantity / quality tradeoff is high) and how resources contribute to the transformation of enrollment to degree attainment. 


\section{Cohort Size and College Completion within States}

Our empirical approach begins with the measurement of the relationship between cohort size and college completion within states. States are a natural unit of analysis because public institutions of higher education are largely under the control of state governments. By looking at changes within states over time, we abstract from broad national changes. While aggregate adjustments in cohort size may affect the returns to college, within-state variation in cohort size should not affect returns in the presence of nationally integrated labor markets. ${ }^{12}$

The empirical analysis in this section focuses on the measurement of the elasticity of college completion, defined as the log of BA degrees awarded, with respect to cohort size. The state is the unit of analysis and all specifications include state and year fixed effects. Thus, regression estimates of collegiate attainment of a cohort on cohort size examine whether the collegiate outcome of a cohort differs when that state and cohort's population changes at a rate different from the national norm.

Given our interest in how cohort size affects the resources available to those considering college attendance, it is natural to measure cohort size at a point when individuals would typically attend college (age 18). We would then like to be able to calculate the fraction of these cohorts that eventually receive a BA degree. Such data do not exist. Measures are available from colleges and universities enumerating the number

\footnotetext{
${ }^{12}$ Larger cohorts may experience somewhat lower returns to education if the substitution between younger and older workers among the college educated is less than complete, thus reducing incentives to complete college in aggregate. A long research literature (e.g., Welch, 1979; Stapleton and Young, 1988) focuses on the question of how adjustments of the labor market to relatively large cohorts affect incentives to invest in education for relatively large cohorts. Using Census data, we find no evidence of variation in state-specific college/high school wage differentials with cohort size. In addition, while state specific cohort size is (negatively) associated with state specific unemployment rates, we also find no evidence of any association between unemployment and college completion rates (see also Card and Lemieux, 2000;
} 
of degrees conferred each year (we refer to this as "institutional data"). Alternatively, the decennial Census allows researchers to calculate degree completion by state of birth, but does not identify state of residence at age 18. Using both sources of data allows us to check the potential effect of the differences between the two data sets on our estimates of crowding.

We begin with the presentation of results based on institutional data and then turn to results employing Census data. Finally, we discuss possible explanations for the differences between the two sets of results. In the main, results using Census and institutional data tell a very similar story: increases in cohort size are not accompanied by commensurate increases in collegiate attainment.

\section{Results Based on Institutional Data}

Table 2 begins the empirical analysis with the estimation of the elasticity of college completion, defined as the log of BA degrees awarded, with respect to cohort size, defined as the size of the population age 18 within the state four years earlier. ${ }^{13}$

Estimates are presented for two periods: 1954-1996 and 1967-1996. Columns (1) and (2) show that the elasticity of college completion at all institutions with respect to cohort size is significantly less than one, varying from .71 to .62 depending on the period of

observation. In addition, the estimate in column (3) for the effect of cohort size at age 18 on the number of degrees awarded by public institutions is broadly similar to the estimate

Fitzpatrick and Turner, 2006). These estimates suggest that the primary effect of variation in state-specific college-age population size on college completion rates cannot be working through labor market incentives.

13 Thus, for example, we related BA's produced in Michigan in 1990 to the size of the 18 year old population in the state in 1986 . The choice of this four year lag was dictated by the fact that 22 is the modal age at which individuals receive their BA in the U.S. 
of overall effect (.59 vs. .62) over the period for which this distinction is possible. ${ }^{14}$

Another variable of interest in measuring higher educational attainment is enrollment.

Enrollment represents an "input" to educational attainment while degrees awarded are an outcome. For this reason, we regard degrees received rather than enrollment as our primary outcome and would expect effects of cohort size on enrollment to be more muted than the effects on degree completion. Using measures of total enrollment presents a story similar to the regressions for degree outcomes. With the log of total enrollment as the outcome in columns (4)-(6) of Table 2, estimates of the elasticity with respect to cohort size are larger for enrollment (0.89 and 0.79), while still appreciably less than one in all of the specifications.

Figure 2 plots per-year cohort size and BA production from 1950 to 1995 for selected states. (Similar figures for all states appear in the appendix). It is important to note that while the regressions we reported in Table 2 took out year effects, much of the observed variation in these figures represents the growth and decline of the overall size of the college-aged population. For each of the states shown, the 1950s and 1960s saw a very dramatic rise in both cohort size and the number of individuals receiving BA degrees. However, around 1970 BA production leveled off and remained approximately constant in the subsequent 25 years, despite an expansion in cohort size through the 1980s and a drop in cohort size thereafter. The figures give the strong impression of capacity constraints and the absence of full elasticity in supply. During the 1950s and 1960s many states were investing heavily in higher education. As a result, capacity,

\footnotetext{
${ }^{14}$ Following Fortin (2003), one might be concerned that the market adjustments in states with smaller private higher education sectors would be different from those in states with larger private higher education sectors. Interacting cohort size with an indicator for states with public higher education enrollment below the median does not yield a significant effect.
} 
enrollments, and BA production expanded rapidly. Starting in the 1970s, investments leveled off and capacity and enrollments remained relatively fixed.

The pattern observed in Figure 2 suggests that, while BA production might not have dropped much during periods when cohort size was shrinking, it would increase during periods when cohort size was increasing. This kind of asymmetric pattern of adjustment might arise if it were politically harder to shrink than to expand higher education. To check on this notion, we re-estimated our regression models using the period before and after 1970. The point estimates suggest that, if anything, crowding out (i.e., the less-than-proportional increase in BA production relative to cohort size) was more severe before 1970s than it was after, though the difference was not statistically significant. More generally, our results do not depend on the period or set of years chosen for analysis.

Still, there are a number of reasons why the institutional measure of BA production regressed on cohort size at age 18 might tend to exaggerate the magnitude of cohort crowding. It would not be too surprising to find that being born into a large (statespecific) cohort would tend to increase the odds that a person went out of state to attend college or temporarily postponed going to college. In either case our estimates based on the institutional data, would overstate the magnitude of the effect of cohort size on college completion (crowding). The Residence and Migration survey, which has been conducted periodically by the Department of Education since the 1940s, provides some information on enrollment by state of residence and college. We estimate the elasticity of total enrollment at the state level with respect to population $[0.61(0.11)]$ and the elasticity of enrollment of state residents with respect to population [0.62(0.08)]. If 
increased out-of-state enrollment were a substantial part of the response to cohort expansion, we would see larger elasticities (closer to 1) for enrollment of state residents than for total enrollment in the state. Yet, the elasticities for these two measures are virtually identical. The available empirical evidence does not support the notion that relatively large cohorts of college students are "absorbed" by neighboring states. In fact, it appears that the enrollment behavior of state residents is closely tied to in-state college opportunities, with elasticities very close to the estimates using the full panel of BA degree data in Table $2 .^{15}$

In addition, it seems plausible that time to degree may tend to rise with cohort size. If college-age individuals in large cohorts face fewer resources, they may find college less attractive, and marginal students might delay college enrollment. ${ }^{16}$ What is more, fewer resources might translate into slower progress while in school. Empirically, calculations using the Current Population Survey suggest that increasing cohort size does increase the age at degree receipt ${ }^{17}$, though the magnitude of this effect is by no means large enough to explain the overall effect on completion rates. One concern is that, in the institutional measures of degree attainment, increases in time to degree will tend to bias estimates of the effect of cohort size on the number of BAs produced per cohort; yet, such errors should be offsetting as time to degree expands and contracts with cohort

\footnotetext{
${ }^{15}$ Focusing on just the flagships schools, we do find that out-of-state enrollment tends to fall in the face of large cohorts; however this effect is small enough and the flagship schools represent a small enough share of total enrollment, that this pattern hardly shows up when we combine data on all colleges and universities.

${ }^{16}$ If shifts in population size occurred at fairly high frequency, individuals who are part of particularly large cohorts might find it optimal to postpone college for several years. However, this kind of substitution is unlikely to be plausible in large scale as, as we will see, most of the movements in cohort size observed occur at relatively low frequency. Moreover, such inter-temporal adjustment would likely reduce the number of years over which an individual would get the benefits of a college education, thus reducing the return to the degree.

${ }^{17}$ Falaris and Peters (1992) find similar patterns using NLS and PSID data.
} 
size ${ }^{18}$ All in all, we doubt these inter-temporal substitution effects have much effect on our estimates.

We should note that with the census data we can directly measure cohort completion rates. As a result, effects of cohort size on the location or timing of degree completion will not affect our estimates of the relationship between cohort size and degree completion. Results Based on Census Data

An alternative way to measure the effect of cohort size on degree completion employs Census micro data on BA completion rates, organized by state of birth withbirth cohort size as the relevant demographic variable. ${ }^{19}$ Using alternative data sources serves to underscore the reliability of our results while necessarily answering somewhat different questions. Table 3 presents estimates of the effects of cohort size (measured in terms of year and state of birth) on degree completion using Census data, along with

\footnotetext{
${ }^{18}$ A simple example will illustrate. Suppose that the fraction of a cohort ultimately receiving a BA remains constant, but cohort size grows at a rate of $1 \%$ per year. Also suppose that, as a result of the increase in cohort size, the age at which individuals typically receive their BA rises from 22 to 23 years over a 10-year period. During this period we would observe an approximate $10 \%$ increase in the size of the population, but only a $9 \%$ increase in the size of the number of BAs. As a result, we would underestimate $\partial \ln (B A) / \partial \ln (P o p)$ by about $10 \%$ - or estimate crowd out when none exists. This example might make it seem as if the data we are using will lead us to overestimate crowd out effects. However, if one runs this thought experiment in reverse, one sees that during periods of declining cohort size (and decreased time to degree), we will tend to overestimate $\partial \ln (B A) / \partial \ln (P o p)$. Since the variables we use in our regressions are all deviations from year and state means, some states will be experiencing increases in cohort size (relative to the mean), while others are experiencing decreases in cohort size, and the bias introduced by the fact that we are using period rather than cohort measures will tend to cancel out.

${ }^{19}$ Note that when we use Census micro data organized by state and year of birth to measure the college completion rates, the regression estimates with the dependent variable specified as a completion rate $(\ln [B A / N])$ are not equal to the specification in levels $(\ln [B A])$ minus one. The reason is that that the denominator in the measure of the completion rate, a measure of cohort size calculated from the micro data, is not identical to the population measure from Vital Statistics sources. What we observe in the data is a negative correlation between the error (the difference in the measures) and the measure of population from the Vital Statistics source. While the simple correlation between the population measure from the Vital Statistics and the population measure from the Census micro data is 0.996, a regression of the Census measure on the Vital Statistics measure (both measured in logs), produces a coefficient of .952 (.0127). The result is that regression estimates using the Census micro data in levels will produce estimates suggesting a
} 
estimates of the effects on degrees conferred using the institutional data for comparison. Because the dependent variable for the Census-based estimates is the cohort share (fraction with a BA) while for the institutional-based results it is the number of BAs, subtracting one from the latter results will put these two estimates on the same footing. Regressions of the share of the population born in each state and year with a BA degree on cohort size (this time measured with cohort size at the year of birth) show a substantial decline in college completion shares with changes in cohort size. The magnitude of the estimated decline when using the Census data is somewhat smaller than the magnitude of the decline when using the institutional data - that is -0.26 or -0.24 versus -0.34 or -0.29 , but the differences between the point estimates are not qualitatively important, nor are they statistically significant. ${ }^{20}$

To address the potential concern that the identification of the effect of within-state changes in cohort size on degree attainment is entirely a reflection of broad demographic shifts, we add state-specific linear trends to the baseline specification. Results are reported in the even-numbered columns of Table 3. While including state-specific trends in the specifications using Census data tends to weaken the evidence for "crowding out," doing so in the specifications using institutional data strengthens it, though perhaps implausibly (even columns, bottom row of Table 3). Understanding the large difference between the results based on the institutional data and the Census data with the inclusion of state-specific trends would certainly seem to be important. Possible explanations

lower elasticity of completion with respect to population than related estimates with the dependent variable specified as a completion rate.

${ }^{20}$ These estimates are quite similar to those presented in Card and Lemieux (2000). Depending on the specification and cohorts used in their regressions, they estimate a $10 \%$ increase in cohort size is associated with a decline in college completion of between 0.4 and 0.8 percentage points for men and between 0.3 and 0.6 percentage points for women. To convert these estimates into elasticities, one needs to 
include differences between the two in the timing of the cohort-size variable and the potential for significant measurement error in the state-specific measure of population at age 18 .

Given our maintained hypothesis that the primary reason for the association between cohort size and college completion rates involves cohort crowding at colleges and universities, the right measure of cohort size is the cohort size during the typical college going years. Cohort size at birth can then be thought of as an error-ridden proxy for cohort size 18 years later. Under the assumption that the variable we wanted to include in these regression was the size of the population in a person's state of residence when the person was in high school, we use Census data to calculate the magnitude of the attenuation bias associated with using the size of the population in the person's state of residence at birth. To do this we use data on 15-17 year olds in the 1960-1990 Census and regress the log of current state-specific cohort size on the log of the person's state specific birth cohort size, controlling for state and year effects. The coefficient on the birth cohort variable in these regressions is $0.56(0.10)$, implying a downward bias if $44 \%$. Once state specific trends are included in the regression, the coefficient drops to 0.30 (0.06), implying a downward bias of $70 \%$. We use these estimates to adjust our Census-based estimates, with corrected estimates reported in the second row of Table 3. These corrected results are remarkably consistent across specifications and years - the estimates imply that a $10 \%$ increase in state specific cohort size reduces college completion rates by about $4 \%$. The corrected Census based estimates are also similar in 
magnitude to the estimates based on institutional data that do not include state-specific trends.

Because including state-specific trends eliminates more than $80 \%$ of the variation in our key explanatory variable, one natural hypothesis is that the introduction of statespecific trends seriously exacerbates the impact of measurement error in our cohort size measures on outcomes. The intercensal estimates of cohort size at age 18 are based on imputations that, importantly, involve Census estimates of migration flows, which may reflect divergence from the actual level of the population within a state in a given year. ${ }^{21}$ Gauging the direct effect of these errors on our estimates would be difficult if not impossible. Notably, the Vital Statistic data that we use to construct the birth cohort size variables used in our analysis of Census data does not suffer from the same kind of measurement error problems generated by imputation.

Regressions that use institutional measures of degree attainment (without statespecific trends) produce estimates of the effect of cohort size on college completion that are close to the ones we obtain using Census data adjusted for the imperfect link between cohort size at birth and the size of cohorts at the time of college entry. With this adjustment, Census-based estimates produce nearly the same estimated elasticity of college completion with and without state-specific trends, and these point estimates actually suggest slightly more crowding than those estimates relying on institutional data. Overall, these results are consistent with the interpretation that the "crowding" that matters occurs at the collegiate level.

\footnotetext{
${ }^{21}$ Some evidence on the magnitude of the errors introduced by the census imputations comes from comparing estimates based on imputations to estimates based on actual enumerations. Comparisons between Census projections of the college-age population in each state in 2000 benchmarked to the 1990
} 


\section{Understanding the Variation in our Population Measures}

Geographic shifts in the location of economic activity in the U.S. generate migration across states, with regions in the South and West growing much more rapidly than those in the North East and North Central, and generate much of the variation in the cohort size measures. Geographic mobility of adults of childbearing age and those with children generates changes in the size of the pool of potential college-age students within-states some years later. Indeed, the within-state-and-year correlation between the size of the 18-year old population and employment (both measured in logs) is 0.72 (the correlation between the size of the birth cohort and employment is 0.67 ).

To get a perspective on the time series properties or our population measures, we employ Fourier decomposition following Baker, Benjamin, and Stanger (1999), and we find the vast majority of the total variation in the data in the low frequency range. ${ }^{22}$ Indeed, with either population variable, over two-thirds of the variance occurs at the lowest two frequencies identified in the data (frequencies corresponding to periods of 44 and 22 years), before state specific trends are taken out. Even with the inclusion of state specific trends, three-fifths of the variation occurs as the lowest two frequencies.

State-specific shifts in the size of the college-age population tend to be slow and steady and are, as a result, highly predictable. The predictable nature of changes in the size of the college-age population within states and the observation that growing states may experience less budgetary pressure would, at the surface, mitigate against findings of

enumeration to counts from the 2000 enumeration show an average gap of roughly $4 \%$, with some errors being as large as $20 \%$ !

22 With 43 years of data (1954-1996), we employ the Fourier decomposition to divide the measure of cohort size into 22 orthogonal components at varying frequencies (from 0 to $\Pi$ ) according to: 
substantial crowding out at the postsecondary level. That such effects exist, given the nature of the variation in cohort size, point to the importance of substantial capital subsidies in higher education and the limited degree of supply-side adjustments at those institutions like research universities.

\section{Cohort Size and Collegiate Supply-Side Responses}

To understand the mechanism behind the limited adjustment of collegiate attainment with increases in cohort size, we consider the potential supply-side adjustments of colleges and universities. Potential margins of adjustment include price (tuition) and resources per student, with changes in these avenues potentially differing by type of institution.

\section{Tuition adjustments}

For public institutions, tuition covers such a small fraction of total costs and there is such an unusual link between political actors at the state level and public colleges and universities that tuition (price) may not serve as a plausible channel for adjustment to demand shocks and other market forces. Indeed, the evidence from regressions of the tuition charged to in-state students by public colleges and universities on cohort size points clearly in the other direction: a $10 \%$ increase in cohort size is associated with a $2.7 \%$ decrease in tuition at the state comprehensive schools and $4.2 \%$ decrease at flagship institutions. As in previous specifications, these regressions include state and year fixed effects. Since there were secular increases in tuition at state schools over the period under study, the right way to think about these results is that they suggest that tuition rose less

LnPop $=\sum_{k=0}^{21}\left(\xi_{k} \cos \left(2 \pi \frac{k(t-1)}{43}\right)+\gamma_{k} \sin \left(2 \pi \frac{k(t-1)}{43}\right)\right)$. The parameters $\xi_{\mathrm{k}}$ and $\gamma_{\mathrm{k}}$ are estimated in a regression for 
rapidly in states that experienced population growth over the period in question. ${ }^{23}$ It is only among the non-research private institutions that we see a positive link between tuition and cohort size.

\section{Non-tuition revenue sources}

Beyond tuition levels, we consider the relationship between cohort size and other sources of revenue, including federal support and appropriations from state sources. Not surprisingly, variation in federal support to colleges and universities is quite inelastic with changes in cohort size, with an elasticity of about $0.27(0.19)$, net of state and year fixed effects for the interval from 1950-1996. State appropriations demonstrate a bit more adjustment to cohort size, with an elasticity of $0.58(0.11) .^{24}$ This estimate is remarkably similar to the estimates we report in Tables 2 and 3 of the effect of cohort size on college completion rates, which is consistent with our notion that the source of these effects is college resources. ${ }^{25}$ While we do not have a full series, it seems implausible that private philanthropy would adjust perfectly to changes in cohort size. Given the overall enrollment elasticities in Table 2, it is clear that non-tuition revenue sources per student decline in the face of increases in cohort size.

\section{Differences by type of institution}

each state, leading to the estimate of each of the 22 Fourier components for each state and year.

${ }^{23}$ When state employment is included in the regression, the effect of cohort size on tuition approaches zero, with increases in state employment having a substantial negative effect on tuition prices. These results would seem to confirm the notion that states tend to raise tuitions when state economies are in trouble and state budgets are tight.

${ }^{24}$ The measures of state appropriations used in these regressions are from the Department of Education's institutional survey of college and university finances which extends from 1950 to 1996. Measures of state appropriations from state-based finance surveys, which are available only after 1960, are strongly correlated and yield a slightly smaller elasticity with respect to cohort size.

${ }^{25}$ As these estimates suggest, a regression of the log of the number BA degrees awarded on the $\log$ of state appropriations (including state and year effects), using cohort size as an instrument, yields an estimated coefficient that is close to and not statistically distinguishable from 1. 
Variation in relative adjustments in resources and enrollment across institution types is to be expected from the differences in the objective functions of colleges and universities. Community colleges and four-year institutions with modest admission requirements tend to place "access" at the center of their mission, attempting to provide enrollment opportunities for all applicants who meet minimum qualifications. At the other extreme, research universities and liberal arts colleges are likely to emphasize the role of student quality and resources per student as they make choices at the margin between quality and quantity. These considerations suggest that we should find substantial accommodation among two-year institutions to changes in cohort size and little accommodation (and, perhaps, a ratcheting up of selectivity) among universities.

The regression results in Table 4 show the elasticity of enrollment and BA completion with respect to cohort size (measured at age 18) by type of institution. In the public sector, we distinguish community colleges, flagship institutions (the highest ranked public university in the state), and other four-year institutions. In addition to presenting the total for all private institutions, we distinguish the unique and highly subsidized set of research universities and liberal arts colleges. At one extreme, cohort size has a coefficient that is close to 1 at the two-year colleges, indicating that at these institutions enrollment levels fluctuate markedly with changes in cohort size. Among public institutions awarding at least a BA degree, the flagship institutions are much less responsive in degrees awarded and enrollment to changes in cohort size than the other four-year institutions. At the other extreme, the elasticity of enrollment with respect to cohort size is close to zero at the private liberal arts colleges and universities. (If these institutions are in fact operating in a national rather than regional market, then they would 
not face demand shocks at the state level - e.g., if there is a $10 \%$ population shock in New Jersey, the change in applications to Princeton would be appreciably less than the change in applications to Rutgers.)

The likelihood of completing college differs markedly with the institution where an individual starts in the higher education pipeline, even after accounting for composition differences between the student bodies. Perhaps the most visible margin of differences in completion rates occurs between the two-year and four-year institutions. Reynolds (2006) finds that college students starting at two-year schools with the intention of completing a BA and observable characteristics paralleling students at four-year schools are much less likely to complete the BA than their peers beginning at four-year schools. $^{26}$ The probability of completing a BA is 0.48 for men, relative to 0.62 among students starting at four-year institutions, and 0.59 for women, relative to 0.76 among students starting at four-year institutions. It follows that part of the effect of cohort size on college completion rates works through the effect of cohort size on the nature of the institutions students attend, with larger cohorts pushing a higher share of college students to community colleges and open-access four-year institutions which tend to be more limited in resources per student than state flagship universities.

\section{Changes in College Preparedness and Compositional Changes}

Within states, large cohorts are less likely to complete college than relatively small cohorts. As discussed, adjustments on the supply side of the market provide one explanation for this result. An alternative explanation is that changes in the demand for college may be reduced among relatively large cohorts if college preparation is also 
linked to cohort size. At issue in this analysis is whether results we attribute to adjustments on the supply-side of the higher education market are instead related to demand-side explanations. Two related concerns surface. First, relatively large cohorts may be distinguished by adverse demographic or economic shocks that have direct effects on collegiate attainment. For example, if big cohorts are distinguished by low parental education or large family size, such "compositional effects" might account for reduced college completion rather than crowding out on the supply side of the market. Secondly, membership in a relatively large birth cohort may dilute educational resources at the elementary and secondary levels, which would also reduce college preparedness. Both types of effects imply that the change in college demand may be far less than a change in cohort size.

To understand how compositional factors such as race, parental education, and family size are tied to cohort size, we examined 16 year-olds (as 18 year-olds are less likely to appear with their parents in the data) and their parental characteristics by state for the 1970, 1980, and 1990 decennial Census enumerations. Regressions of a particular parental demographic characteristic (e.g., share black or number of children) on the size of the 16-year-old population in a state and Census year, with year and state fixed effects, provides an indication of how changes in cohort size are tied to observed demographic characteristics. More children in a family imply fewer resources per child, and educational attainment—both formal and informal—is likely to be negatively affected by a decrease in the time and financial resources available to each child within the family (Becker, 1981; Willis, 1973). Similarly, other family characteristics such as maternal

\footnotetext{
${ }^{26}$ Reynolds' finding using matching estimators echoes earlier work using regressions to adjust for observable differences between those starting at two and four year schools (Rouse (1995), Leigh and Gill
} 
education, family structure, and race may affect the educational resources available outside of schools.

For the most part, we find effects that are not statistically significant and economically small. This applies to measures of family size, parental education, and ethnicity. When we weight by state size, the only significant effect is on Hispanic ethnicity, with a coefficient of .27 indicating that a $2.7 \%$ increase in the share of collegeage students of Hispanic origin would follow a $10 \%$ increase in the size of the 16-yearold population. Even with the upper end estimates of the effect of Hispanic origin on college completion, these compositional effects could not explain a sizable share of the reduction of college completion with increases in cohort size. ${ }^{27}$

Individuals in relatively large cohorts may also face diminished resources in elementary and secondary schools, with these resource effects reducing college preparedness and completion. Examination of the link between resources per student at the primary and secondary levels and cohort size helps to place this question in perspective. First, resources per student are negatively affected by increases in cohort size at the elementary and secondary levels. Using data for the 1970 to 1995 period, we find that variation in K-12 enrollment and in average daily attendance is linked to lower levels of teachers per student, with coefficients $-0.18(0.06)$ and $-0.16(0.05)$ respectively which represent elasticities from the $\log -\log$ specification. ${ }^{28}$

(2003), and Sandy, Gonzales and Hilmer, forthcoming) community.

${ }^{27}$ Additional evidence suggests that the increase in the fraction of the population that is Hispanic can explain little, if any, of the crowd out effects we estimate. The association between population growth and the growth in the share of the population that is Hispanic largely reflects secular trends in the Southwest, trends that are controlled for in our specifications that include state-specific trends.

${ }^{28}$ Because it is not possible to distinguish enrollments and class size accurately at the grade level, year and state aggregates over all elementary and secondary (K-12) enrollment form the variables of interest. Data are from Statistics of State School Systems (1998) for 1970-1995. Average Daily Attendance is from Table 13, Fall elementary and secondary enrollment is from Table 10, and teachers per student is 
What effect might these changes in resources available to K-12 students have on college achievement? While an increasing number of research papers find a significant effect of class size on student achievement (e.g., Krueger, 1999), most of these estimates measure the effect of lower class size in a single year on achievement. Because we are interested in the cumulative effects of class size on educational attainment, existing estimates of the effect of class size on test scores do not provide an appropriate basis for inference. Instead, following Card and Krueger (1992), we use the average of the potential pupil-teacher ratio faced by the student in a state. Using measures of collegiate attainment from Census data, we find significant effects of the teacher-student ratio for all Census years examined. ${ }^{29}$ The estimated effect of teacher-student ratio on college completion for the 1926-1975 birth cohorts in the 2000 Census is large - $0.46(0.15)$, with both collegiate attainment and resources measured in logs. Such evidence is indicative of reductions in college preparedness associated with resource declines in large cohorts, but likely represents an upper bound of the causal effect of the teacher student ratio on attainment because state-level changes in the student-teacher ration are likely correlated with other policy changes affecting attainment, including lengthening the school year and investing in higher education. ${ }^{30}$ Still, combining the effects of enrollment on resources and resources on degree attainment $\left(\frac{\partial \ln B A}{\partial \ln \text { Teachers / Student }} \times \frac{\partial \ln \text { Teachers / Student }}{\partial \ln \text { Pop }}\right)$, suggests that the effect on college

derived from the Pupil-Teacher Ratio reported in Table 24. The specifications used to estimate these numbers include state and year effects; adding state specific trends had little impact on the estimates.

${ }^{29}$ The dependent variable is the share of college graduates in each state and birth cohort, measured in logarithmic form. Pupil-teacher measures were provided by Alan Krueger and reflect the potential resources available to students in the K-12 years. All regressions include state and year fixed effects. 
completion operating through resources is likely to be quite modest (0.07 to 0.08$)$. While demand-side effects are plainly not zero, and the impact of cohort size on precollegiate academic achievement is an interesting question in its own right, these effects are plainly too small to explain the entire effect of cohort size or resources on collegiate attainment. $^{31}$

Some additional evidence indicates that the cohort size effect on college preparedness is not the major factor behind the strong negative association between college completion rates and cohort size. Using data from the College Board's Annual Survey of Colleges, which includes institution-level characteristics of the undergraduate class and admission process from 1986-2000, we found that a $10 \%$ increase in a withinstate cohort size was associated with a roughly $1.1(0.4)$ percentage point rise in the fraction of college students with a GPA of 3.0 or better, and a 2.9 /2.7 (0.8/0.7) percentage point rise in verbal/math SAT scores. Given problems with these data, including considerable missing data and a relatively short time horizon, we do not want to overemphasize these results, but they are certainly consistent with the notion that the dominant factor effecting the negative association between cohort size and college completion rates is educational crowding out rather than lack of college preparedness.

\footnotetext{
${ }^{30}$ See Loeb and Bound (1996) for a more extensive discussion of this issue. In similar fashion Hanushek, Rivkin and Taylor (1996) argue that state level aggregation is likely to exacerbate omitted variable bias, leading to an overstatement of causal effects.

${ }^{31}$ An alternative way to measure the effects of cohort size on college preparedness is to measure the effect of cohort size on test scores directly. Unfortunately, NAEP scores provide only a limited number of state-specific observations over time. SAT scores at the state level may suffer from changes in the selection of the test-taking population over time. Using data on SAT scores at the state level from 1971 to 2000, regressions of test scores on the log of cohort size with state and year fixed effects yields a coefficient of -43.27 (18.12), implying that a $10 \%$ increase in cohort size would lead to a within-state decrease in scores of less than 4.5 points overall. These effects are modest in magnitude, though indicative of some reduction in college-preparedness with cohort size. More surprising is the link between the share of
} 


\section{Conclusion}

In this paper we have documented substantial cohort crowding effects on college completion rates - our estimates suggest that a $10 \%$ state specific increase in the size of the college age population leads to a $4 \%$ decline in the fraction attaining a BA. Neither growth in out-of-state enrollment nor expansion of private enrollment is sufficient to "absorb" the effects of cohort size on enrollment and attainment at public colleges and universities. The available evidence suggests that this crowding out effect occurs because public colleges are unable to absorb the increased demand for college education, as public resources do not increase sufficiently. While it might seem plausible that large cohorts would reach college age less well prepared to continue their education than small cohorts, our estimates suggest that neither the effects of declines in school quality in the elementary and secondary years nor the effects of changes in the composition of the pool of potential college students associated with large cohorts are nearly large enough to produce the observed negative relationship between cohort size and college completion.

On the supply side of the market, the reduction in college completion with cohort size occurs on two margins. Among institutions, those with the greatest non-tuition resources per student, such as flagship universities, are the least likely to increase enrollment to accommodate relatively large cohorts; still, these universities have the highest levels of college completion. To the extent that the distribution of enrollment shifts away from these resource-intensive institutions, the college completion rate will fall. Within public institutions, those that expand to meet population-related shifts in

eligible seniors taking the exam and cohort size, which is positive and significant. One explanation is that colleges increase requirements for standardized tests with relatively large cohorts. 
demand may face reductions in resources per student, further reducing attainment of enrolled students.

While it is plain that the well-known cyclical variation in state funding for higher education may have deleterious effects on public colleges and universities, it is the more sustained depletion in resources per student accompanying relatively large cohorts that has the significant impact on collegiate attainment and the supply of college-educated workers to the economy. In the coming decade, many states are facing large increases in the college-age population, with serious questions about the capacity of state colleges to meet enrollment demand for these cohorts. ${ }^{32}$ Adding to the demographic pressure on higher education resources created by increasing cohort size are persistently tight state budget circumstances in which higher education competes with entitlement programs and the rising cost of healthcare (Kane, Orszag, and Gunter, 2003).

The impending collision of large cohorts and limited public resources in higher education is not just a predicament for colleges and universities, but a potential crisis in economic growth for decades to come if the flow of college-educated workers to the labor force is further curtailed. Because tuition is a small enough part of the total revenues of higher education, it would take enormous increases in tuition to provide the necessary resources for colleges and universities to expand and maintain quality, with such a shift adversely affecting the level and distribution of enrollment. At issue is how colleges and universities, particularly in the public sector, can raise resources from nontuition sources to expand the pool of collegiate opportunities without diluting quality.

\footnotetext{
${ }^{32}$ For example one report estimated that the number of students seeking to enroll at California's public colleges would rise by 36\% between 2000 and 2010. Former University of California President Clark Kerr has dubbed this projected increase in demand "Tidal Wave II" as nearly three-quarters of the projected growth is strictly attributable to population growth (Schmidt, 1999).
} 
While states have, historically, been central to the development of infrastructure and the provision of subsidy in higher education, the current fiscal constraints and restrictions against deficit funding may limit the capacity of states to make investments in human capital through public colleges and universities. 


\section{$\underline{\text { References }}$}

Baker, Michael, Dwayne Benjamin, Shuchita Stanger. 1999. "The Highs and Lows of the Minimum Wage Effect: A Time-Series Cross-Section Study of the Canadian Law."

Journal of Labor Economics, Vol. 17, No. 2. (April), pp. 318-350.

Becker, Gary. 1981. A Treatise on the Family. Cambridge: Harvard University Press.

Card, David and Alan Krueger. 1992. "Does School Quality Matter? Returns to Education and the Characteristics of Public Schools in the United States." Journal of Political Economy, Vol. 100, No. 1, (February) pp. 1-40.

Card, David and Thomas Lemieux. 2001. "Can Falling Supply Explain the Rising Return to College for Younger Men?" Quarterly Journal of Economics Vol. 116 No. 2 (May), pp. 705-746.

Card, David and Thomas Lemieux. 2000. "Dropout and Enrollment Trends in the PostWar Period: What Went Wrong in the 1970s?" in (J. Gruber, ed.) An Economic Analysis of Risky Behavior Among Youth. Chicago: University of Chicago Press, pp. 439-482.

Cheit, Earl. 1971. The New Depression in Higher Education. Berkeley: Carnegie Commission on Higher Education.

Christal, Melodie. 1997. "State tuition and fee policies, 1996-1997." Denver: State Higher Education Executive Officers.

Falaris, Evangelos M. and H. Elizabeth Peters. 1992. "Schooling Choices and Demographic Cycles." The Journal of Human Resources, Vol. 27, No. 4. (Autumn), pp. 551-574.

Finn, Chester. 1978. Scholars, dollars, and bureaucrats. Washington: Brookings Institution.

Fitzpatrick, Maria and Sarah Turner. forthcoming. "Blurring the Boundary: Changes in the Transition from College Participation to Adulthood." In Sheldon Danziger and Cecilia Rouse, eds. The Economics of the Transition to Adulthood. New York: Russell Sage Foundation.

Fortin, Nicole. 2003. "Higher Education Policies and Decelerating Wage Inequality: Cross-State Evidence from the 1990s.” Mimeo, June.

Goldin, Claudia and Larry Katz. 1999. "The Shaping of Higher Education: The Formative Years in the United States, 1890 to 1940." The Journal of Economic Perspectives, Vol. 13, No. 1 (Winter). 
Goldin, Claudia. 1999. "A Brief History of Education in the United States.” NBER Historical Paper 119.

Graham, Hugh and Nancy Diamond. 1997. The Rise of American Research Universities. Baltimore: Johns Hopkins Press.

Hansmann, H. 1981. "Nonprofit Enterprises in the Performing Arts." Bell Journal of Economics Volume 12, No. 2, pp. 341-361.

Hanushek, Eric; Steven G. Rivkin, Lori L. Taylor . 1996. "Aggregation and the Estimated Effects of School Resources." The Review of Economics and Statistics. Vol. 78, No. 4. (Nov.), pp. 611-627.

Hoxby, Caroline. 2000. "The Effects of Geographic Integration and Increasing Competition in the Market for College Education." Mimeo.

Kane, T. and C. Rouse. 1995. "Labor Market Returns to Two- and Four-Year Colleges: Is a Credit a Credit and Do Degrees Matter?" American Economic Review Vol. 85 No. 3, pp. 600-614.

Kane, T.; Peter Orszag and David Gunter. 2003. "State Support for Higher Education, Medicaid, and the Business Cycle." Mimeo.

Krueger, Alan. 1999. "Experimental Estimates of Education Production Functions." Quarterly Journal of Economics, Vol. 114, No. 2 (May), pp. 497-532.

Leigh, Duane and Andrew Gill. 2003."Do community colleges really divert students from earning bachelor's degrees?" Economics of Education Review, Vol. 22, No. 1, pp. 23-30.

Loeb, Susanna and John Bound. 1996. "The Effect of Measured School Inputs on Academic Achievement: Evidence from the 1920s, 1930s and 1940s Birth Cohorts." The Review of Economics and Statistics, Vol. 78, No. 4. (November), pp. 653-664.

Poterba, James. 1997. "Demographic Structure and the Political Economy of Public Education." Journal of Public Policy and Management 16 (January) pp.48-66.

Reynolds, C. Lockwood. 2006. "Estimates of the Effect of Two Year College Attendance Using Matching Methods." University of Michigan (mimeo).

Rouse, Cecilia. 1995. "Democratization or Diversion? The effect of Community Colleges on Educational Attainment." Journal of Business and Economic Statistics, 13 (April), pp. 217-224. 
Sandy, Jonathan, Gonzalez, Arturo and Hilmer, Michael J. forthcoming. "Alternative Paths to College Completion: The Effect of Attending a Two-Year School on the Probability of Completing a Four-Year Degree" Economics of Education Review.

Schmidt, Peter. 1999. “Applications to California's Public Colleges Predicted to Rise by 36\% by 2010." The Chronicle of Higher Education. October 1.

Stapleton, David C. and Douglas Young. 1988. "Educational Attainment and Cohort Size." Journal of Labor Economics v6 n3 330-61.

Washington State Higher Education Coordinating Board. 2006. "2005-2006 Tuition and Fee Rates: A National Comparison."

http://www.hecb.wa.gov/research/issues/documents/2005-

06TuitionFeesNationalComparison.pdf

Welch, Finis. 1979. "Effects of Cohort Size on Earnings: The Baby Boom Babies'

Financial Bust." The Journal of Political Economy, Vol. 87, No. 5, Part 2: Education and Income Distribution. pp. S65-S97.

Winston, Gordon. 1999. "Subsidies, Hierarchy and Peers: The Awkward Economics of Higher Education." Journal of Economic Perspectives, Vol. 13, No. 1.

Willis, Robert. 1973. "A New Approach to the Economic Theory of Fertility Behavior." The Journal of Political Economy, Vol. 81, No. 2, Part 2: New Economic Approaches to Fertility. (March - April), pp. S14-S64. 
Figure 1: Public university adjustment to changes in cohort size absent changes in subsidy

a. Quality maximization

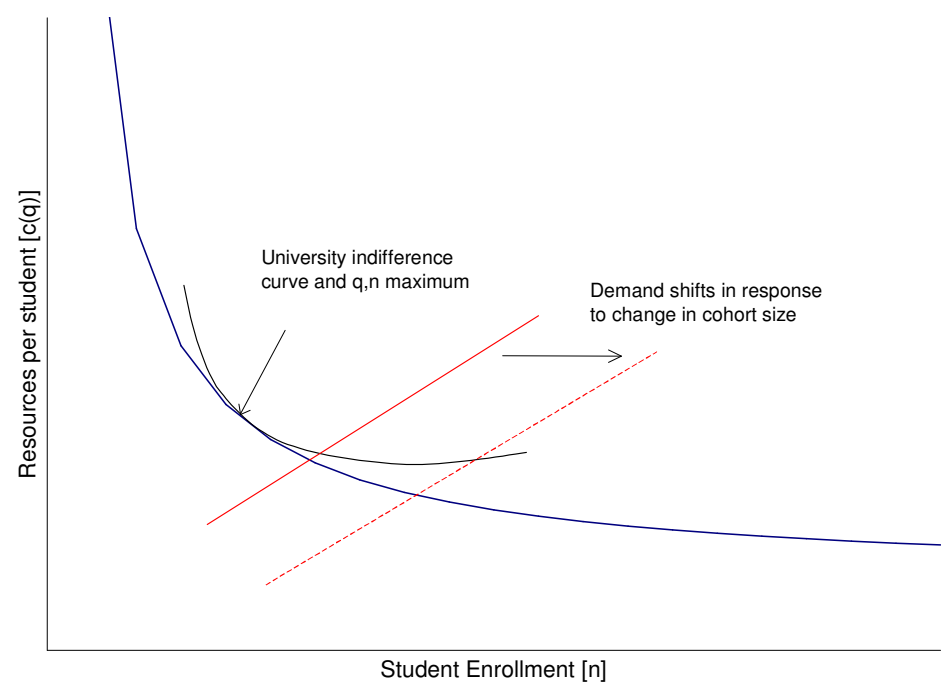

b. Enrollment maximization

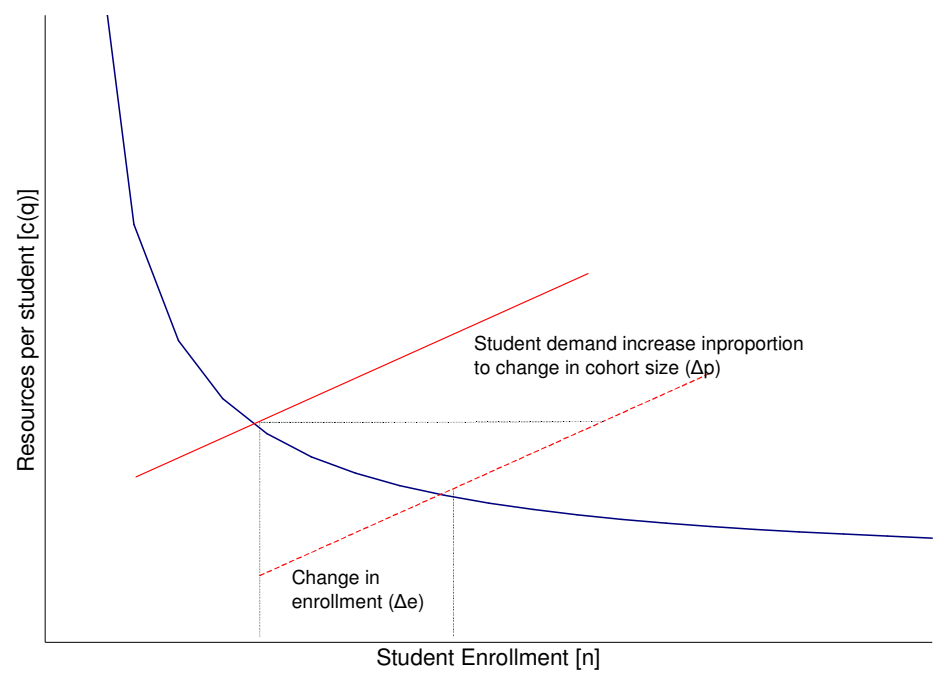

Notes: Collegiate demand is drawn holding tuition constant, with the assumption of exogenous tuition setting. 
Figure 2: State-specific trends in cohort size and BA degrees conferred
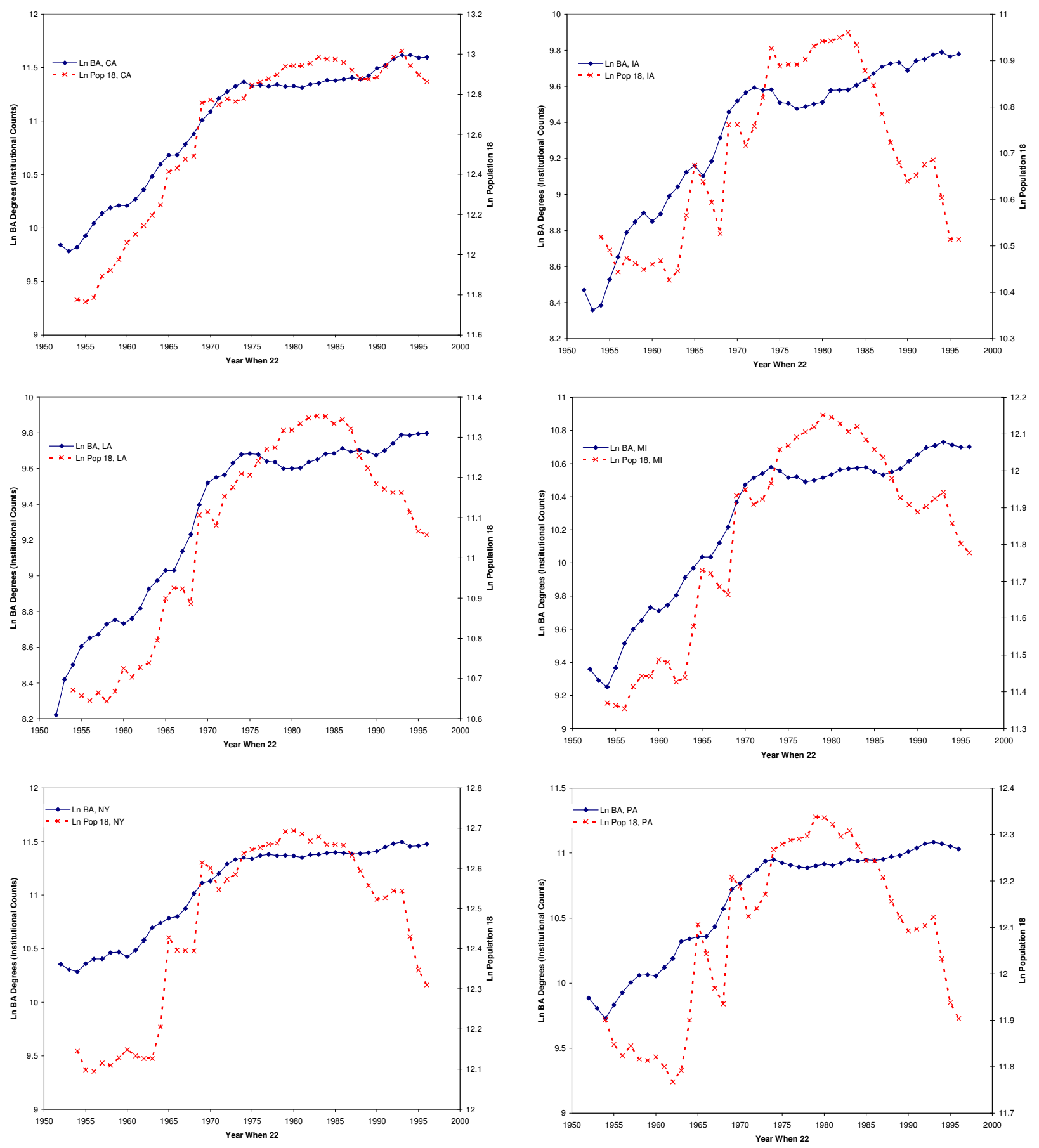
Table 1: Distribution of revenues, enrollment and tuition by type of institution

\begin{tabular}{|c|c|c|c|c|c|c|c|c|c|c|}
\hline & \multicolumn{6}{|c|}{ Current Fund Revenues (1996) } & \multirow{2}{*}{$\begin{array}{c}\text { Undergr. } \\
\text { Enr. Share } \\
\text { (\% of Total) } \\
1996 \\
\end{array}$} & \multirow{2}{*}{$\begin{array}{c}\text { Share of } \\
1 \text { st time } \\
\text { students } \\
\text { in-state } \\
1996 \\
\end{array}$} & \multicolumn{2}{|c|}{ Tuition } \\
\hline & $\begin{array}{c}\text { State } \\
\& \text { Local }\end{array}$ & Federal & Private & Endow. & Tuition & $\begin{array}{c}\text { Aux. } \\
\text { \& Other }\end{array}$ & & & In-state & $\begin{array}{l}\text { Out-of- } \\
\text { State }\end{array}$ \\
\hline Community Colleges & $57.5 \%$ & $11.7 \%$ & $1.0 \%$ & $0.1 \%$ & $20.2 \%$ & $9.5 \%$ & $37 \%$ & $92.7 \%$ & 1,814 & 4,362 \\
\hline Other Public & $36.3 \%$ & $10.7 \%$ & $4.0 \%$ & $0.4 \%$ & $18.3 \%$ & $30.2 \%$ & $33 \%$ & $81.5 \%$ & 2,725 & 6,981 \\
\hline Flagship Public & $29.0 \%$ & $14.8 \%$ & $6.4 \%$ & $1.3 \%$ & $17.2 \%$ & $31.4 \%$ & $9 \%$ & $72.0 \%$ & 3,493 & 9,998 \\
\hline All Private & $2.8 \%$ & $10.3 \%$ & $9.1 \%$ & $5.1 \%$ & $41.9 \%$ & $30.8 \%$ & $21 \%$ & $54.2 \%$ & & 12,881 \\
\hline Research I Private & $2.3 \%$ & $16.1 \%$ & $9.5 \%$ & $5.7 \%$ & $22.9 \%$ & $43.5 \%$ & $2 \%$ & $23.6 \%$ & & 19,814 \\
\hline Liberal Arts Colleges & $1.4 \%$ & $3.0 \%$ & $9.1 \%$ & $10.5 \%$ & $55.5 \%$ & $20.5 \%$ & $2 \%$ & $43.2 \%$ & & 17,648 \\
\hline
\end{tabular}

Notes: Data are from authors' tabulations using U.S. Department of Education, National Center for Education Statistics, Integrated Postsecondary Education Data System (IPEDS), "Finance, 1996-97", "Residence and Migration" and "Fall Enrollment, 1996" surveys. 
Table 2: Regression of BA degrees conferred and enrollment on measures of cohort size

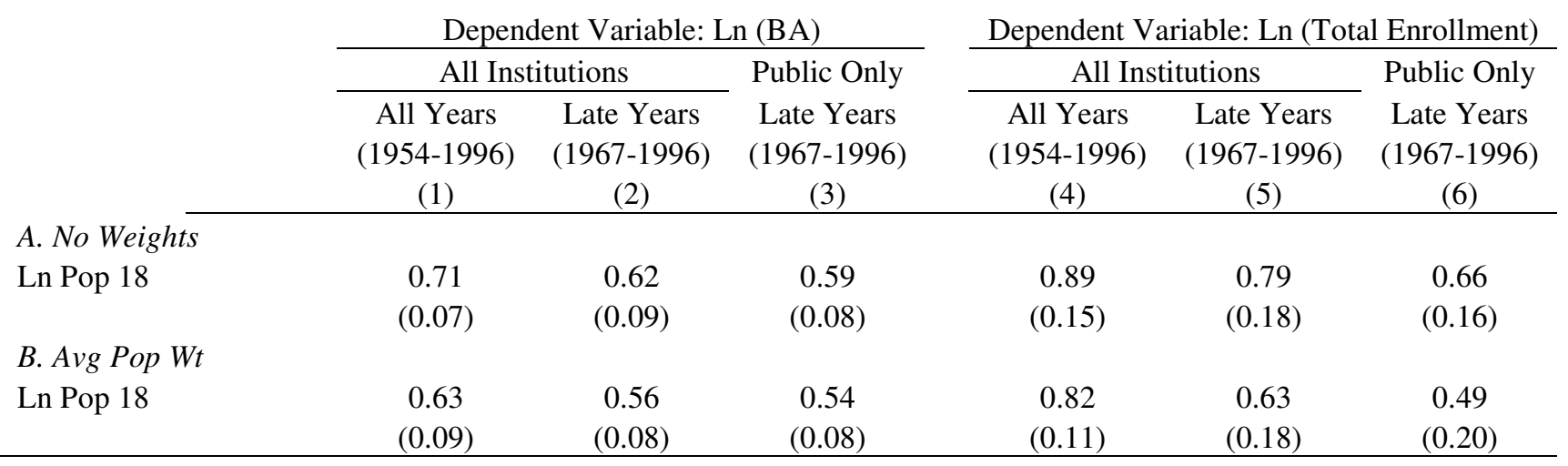

Notes: Degree attainment and total enrollment measures are from institutional measures of degrees conferred. Population data are from single year of age tabulations of the Department of Census. Each specification includes a full set of fixed effects for states and individual years. See Data Appendix for details. 
Table 3: Regression of BA degrees per capita on cohort size, Comparison between Census and Institutional data

1990 Census
1954-87 Degree years
1932-1965 Birth cohorts
$\begin{array}{ccc}\text { (1) } & \text { 1954-96 Degree years } \\ \end{array}$

Census-based share born in state with BA on year of birth population variable

$\begin{array}{lcccc}\text { Ln Pop Coefficient } & -0.26 & -0.11 & -0.24 & -0.13 \\ & (0.05) & (0.03) & (0.03) & (0.05) \\ & & & & \\ \text { Ln Pop Coef. } & -0.46 & -0.37 & -0.43 & -0.43 \\ \text { [Corrected] } & (0.12) & (0.10) & (0.12) & (0.13)\end{array}$

Institutional BA / Pop 18 on population 18 variable

\begin{tabular}{lcccc} 
Ln Pop Coefficient & -0.34 & -0.97 & -0.29 & -0.80 \\
& $(0.09)$ & $(0.09)$ & $(0.07)$ & $(0.08)$ \\
& & & & \\
State Trends & No & Yes & No & Yes \\
\hline
\end{tabular}

Notes: Each specification includes a full set of fixed effects for states and individual years. In the top row, Columns (1)-(2) use observations by year and state of birth from the 1990 Census and Vital Statistics measures of birth cohort size; Columns (3)-(4) use observations by year and state of birth from the 2000 Census and Vital Statistics measures of birth cohort size. The second rows present estimates accounting for the extent to which the birth cohort population is a flawed measure of cohort size at college going-based on individual-level regressions of population on birth cohort size for those 15-17 in the 1960-1990 Census enumerations; standard errors calculated using the delta method. The third row corresponds to results in Table 2, with the difference that the dependent variable is measured as the log of the ratio of BA degrees to cohort size rather than the log of the number of BA degrees. 
Table 4: Effects of cohort size on BA completion and enrollment by type of institution, 1968-1996

\author{
Ln Undergraduate \\ FTE Enr Ln BA \\ on Ln Pop $18 \quad$ on Ln Pop 18
}

$\begin{array}{lcc}\text { Community Colleges } & 0.82 & \\ & (0.37) & \\ \text { Other Public } & 0.56 & 0.82 \\ & (0.13) & (0.22) \\ \text { Flagship Public } & 0.20 & 0.28 \\ & (0.07) & (0.05) \\ \text { All Private } & 0.99 & 1.20 \\ & (0.42) & (0.45) \\ \quad & -0.07 & -0.19 \\ \text { Research I Private } & (0.36) & (0.45) \\ & & 0.71 \\ \text { Liberal Arts Colleges } & 0.26 & (0.17) \\ & (0.17) & \end{array}$

Notes: Data on degrees conferred and enrollment by type of institution are tabulated from institution-level data from the HEGIS/IPEDs. Enrollment data are aligned with the population age 18 in the state in the concurrent year; BA data are aligned with the population age 18 years old in the state 4 years prior, in accordance with the expectation of a four-year modal time to degree. See Data Appendix for further details. Each entry and associated standard error is the coefficient on the log of the population measure in a regression that also includes state and year fixed effects. 


\section{Data Appendix}

The primary sources of data for this analysis are: institutional surveys of colleges and universities, the decennial Census files, the decennial Census publications, population estimates by the Census Bureau, and standard measures of labor markets characteristics.

\section{Population data}

Population measures by state and age are primary to our analysis. There are two sources for our population measures: age-specific estimates from the Census bureau and measures of birth cohort size from the Vital Statistics tabulations.

Measures of birth cohort size for each state from 1928 - 1975 were entered from vital statistics data distributed by the National Center for Health Statistics. The original data came from birth registrations. (These are the cohorts that would have been 22 between 1950 and 1997).

For the most recent three decades, data on population by state and single year of age are available through the Bureau of the Census website. For the years between Census enumerations, these numbers are estimates which take into account mortality and migration. See: http://eire.census.gov/popest/topics/methodology/stage98.txt for a discussion of this methodology. For the years before 1970, we combine data on the state and single year of age enumerations published in the U.S. Census Bureau State Volumes for 1950 (Table 51), 1960 (Table 94), and 1970 (Table 19) and the total population in each state and year for single years from 1950-1970. Because the population measures between census enumerations are estimates, measurement error is a logical concern as discussed in the text.

\section{College enrollment and BA degree outcomes}

The primary measures of collegiate attainment are collected from federal surveys of colleges and universities. The degree data are based on the annual "Earned Degrees Conferred" survey conducted by the National Center for Education Statistics (NCES), which records degrees awarded in the 12-month academic year from July to June. ${ }^{33}$ The enrollment data are from the "Fall Enrollment" surveys which record the number of students enrolled in classes in the fall. Through 1986, these surveys were part of the larger NCES Higher Education General Information Survey (HEGIS), which was subsequently redesigned as the Integrated Postsecondary Education Data System (IPEDS) collection.

${ }^{33}$ In 1960-61, the survey began to separately delineate first professional and baccalaureate degrees. Prior to this point, the two were combined, reflecting the fact that in the early part of the century first professional programs were concurrently undergraduate degree programs at some institutions. 
Historical data (primarily in the years prior to 1966) were entered from published tabulations in the government document publications under the titles "Earned Degrees Conferred" and "Opening Fall Enrollment." Machine-readable data are employed after 1966 (1967 for enrollment), which allows for the distinction of institutions by control (public/private) and Carnegie Classification.

Another source of data from institutional collections is the Residence and Migration Survey conducted periodically by the Office of Education and later the Department of Education. Data for the following years are available: 1949, 1958, 1963, 1968, 1972, 1975, 1979, 1981, 1984, 1986, 1988, 1992, 1994, and 1996. This survey records first-time freshman enrollment by state of residence and state of attendance.

In addition to the data which record degrees awarded and enrollment in each year and state by colleges and universities, the decennial Census enumerations record college attainment to individuals by state of birth and age (or, implicitly, year of birth). As discussed in the text, the Census data are conceptually different from the institutional data in that they do not record the year or state of degree receipt. As is well known, the form of the Census question on educational attainment changed to a degree-based question from an item that recorded years of attainment with the 1990 Census. When we employ data from the 1970 and 1980 enumerations, we treat completing 16 years as equivalent to BA degree receipt.

\section{Higher education finance variables}

Each year as part of the institutional reporting to the federal government, colleges and universities complete a survey of institutional finances in which they report basic income and expense items, including the sources of revenues and expenses. We are particularly interested in distinguishing sources of public support from tuition and fee revenue, while also measuring the total level of educational expenditures. For this purpose, we focus on the state appropriations variable.

State appropriations are those monies received from or made available to an institution through acts of the state legislative body, except institutional fees and other income reappropriated by the legislatures to the institution (i.e. tuition and fees collected by the institution and returned to the institution in the form of appropriations are subtracted as they already appear as tuition and fees). This line item also includes Federal aid received through State channels and regional compacts. We have compared the measures of state appropriations with data reported from state governments on appropriations and found these measures to be highly correlated. Data from state governments are compiled annually since 1960 by the Center for the Study of Education Policy at Illinois State in the Grapevine series. These data differ slightly from measures reported by institutions in that they also include state funds to non-collegiate higher education institutions such as the administrative boards coordinating higher education.

Data on tuition and fees, measured as a price, are available from 1970 to the current year. There are two sources for these data, which provide measures that are highly 
correlated. First, the Department of Education collects data on tuition and fees at the institution level as part of the Institutional Characteristics section of the annual HEGIS/IPEDS surveys. In addition, the Washington Higher Education Coordinating Board conducts an annual survey of tuition and fees at public institutions, which includes data from 1972-73 to the present.

\section{Labor market variables}

Labor market variables used in the analysis include the state specific unemployment rate, personal income and manufacturing wage bill. State-specific unemployment rates are available from 1970 through the Bureau of Labor Statistics [http://www.bls.gov/lau/staadoc.htm]. The personal income and manufacturing wage measures are from the U.S. Department of Commerce, Bureau of Economic Analysis, Regional Accounts Data and are available from 1958 to 2001 [http://www.bea.doc.gov/bea/regional/spi/default.cfm\#s2, the manufacturing wage bill is the s07 series, industry code 400].

In addition, we compute the state- and age-specific measures of the college wage premium in the 1970, 1980, and 1990 Census enumerations. The adjusted average relative wage measures are computed as the return to exactly a BA Degree (or 16 years of completed education) from state-specific hourly wage regressions with a full set of controls for demographic and labor force characteristics including, race, sex, and parttime status.

\section{Primary-secondary school quality measures}

Measures of school quality experienced for students of different states and ages are from the data assembled by Card and Krueger (1992; see Appendix A of this paper) for the analysis of the effects of school quality on earnings. The original source for these data is the Biennial Survey of Education in the United States and related materials. The specific measures employed in this analysis were the pupil-teacher ratio, average term length, and average teacher salary from academic year 1919-20 to academic year 1965-66 (coded by C-K as 1920-1960 for even years). To provide a single measure of school quality for each single year birth cohort, we averaged the potential school quality experienced from ages 6 to 17 within a state. In examining the contemporary relationship between school resources and enrollments, we used data from Statistics of State School Systems (1998) for 1970-1995, which records data on enrollments and resources (both expenditures and class size). 
Appendix Graphs: State-specific trends in cohort size and degrees conferred
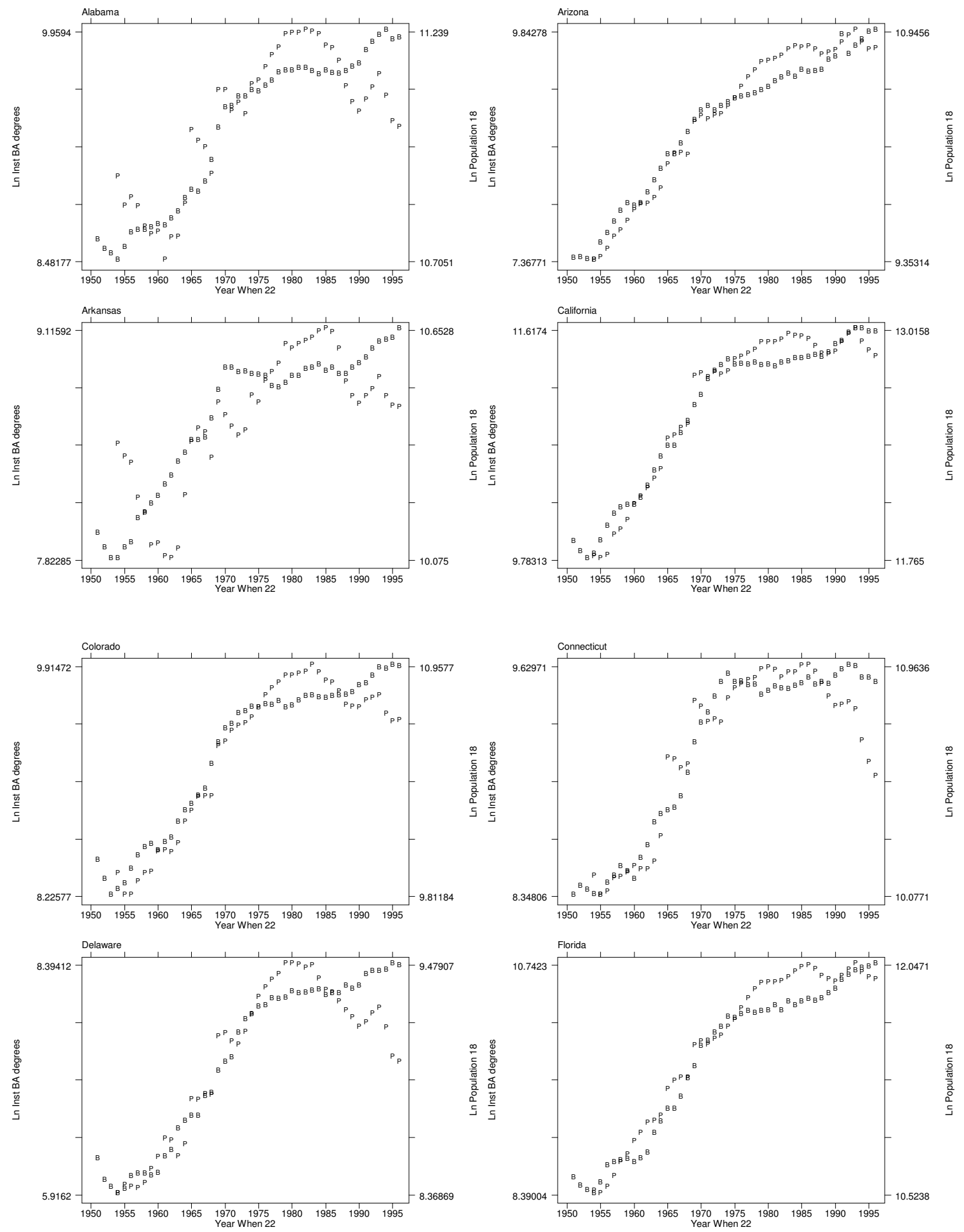

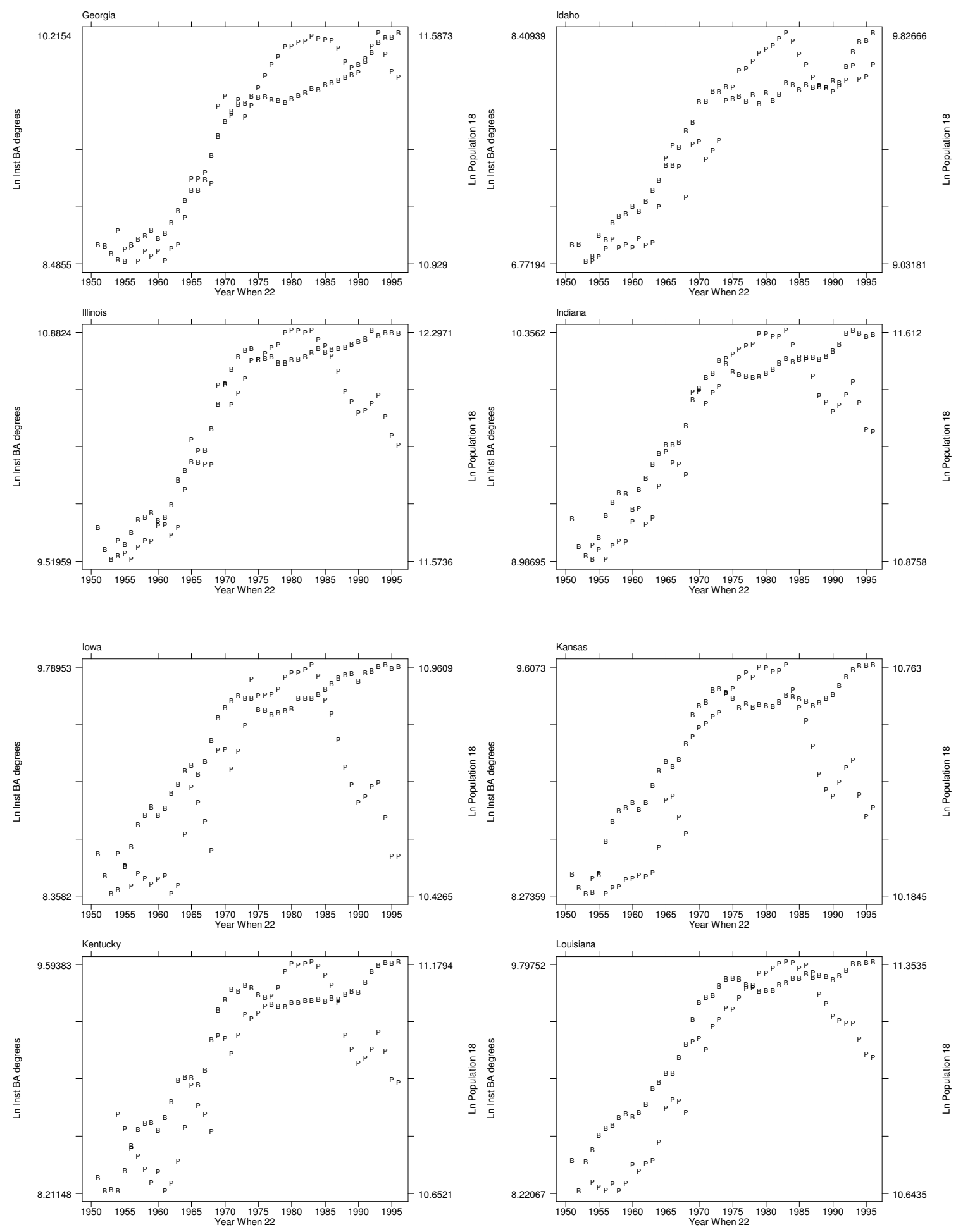

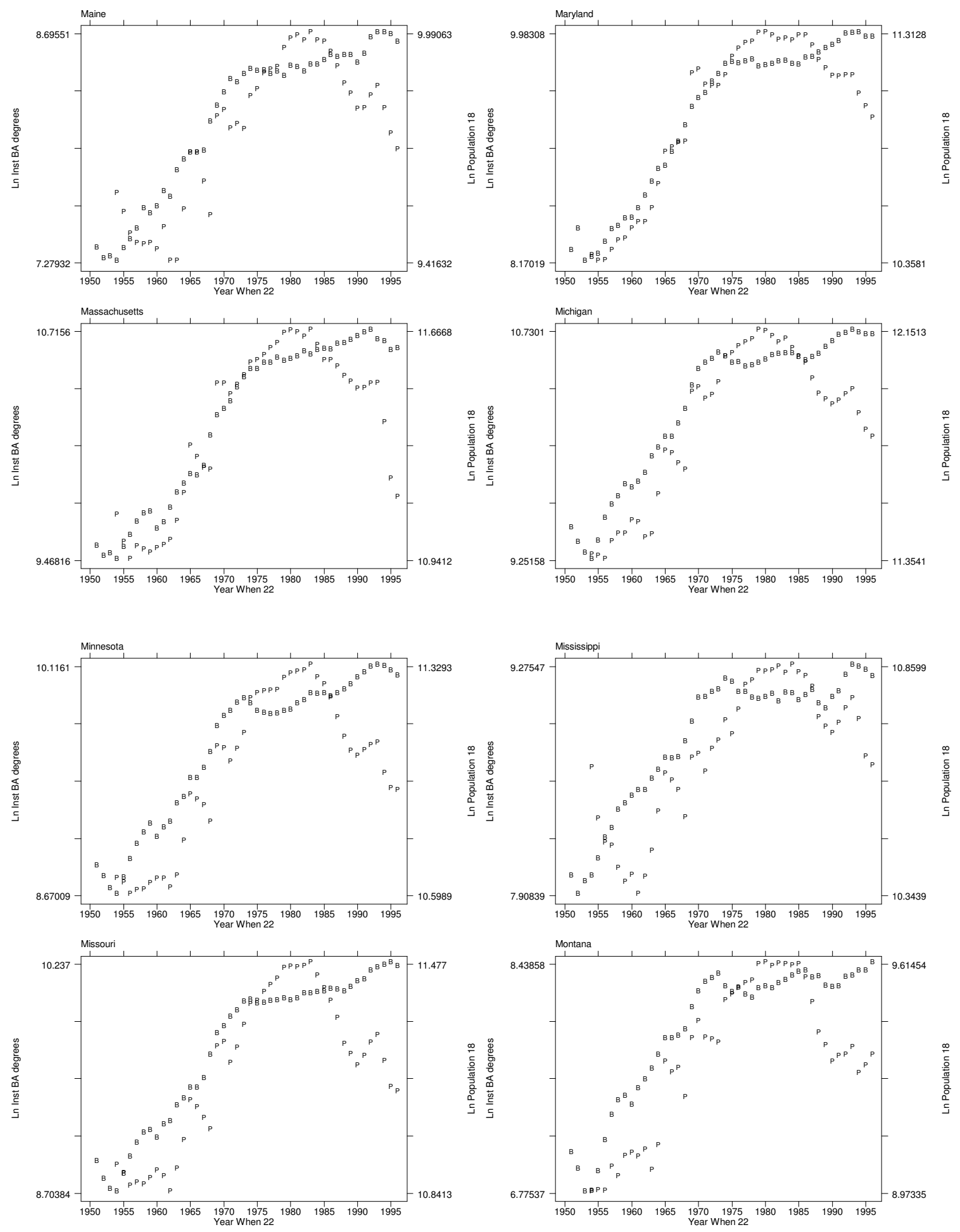

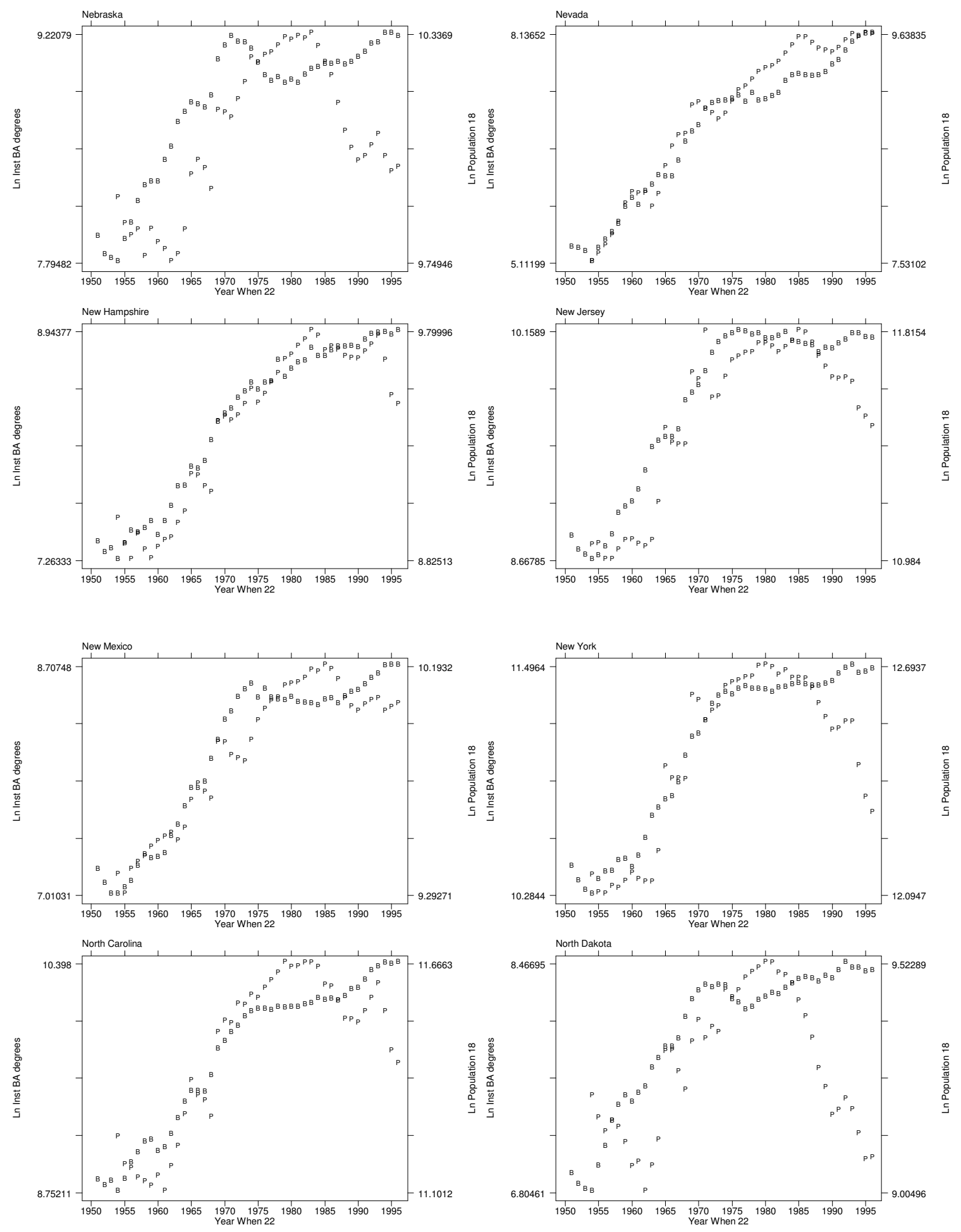

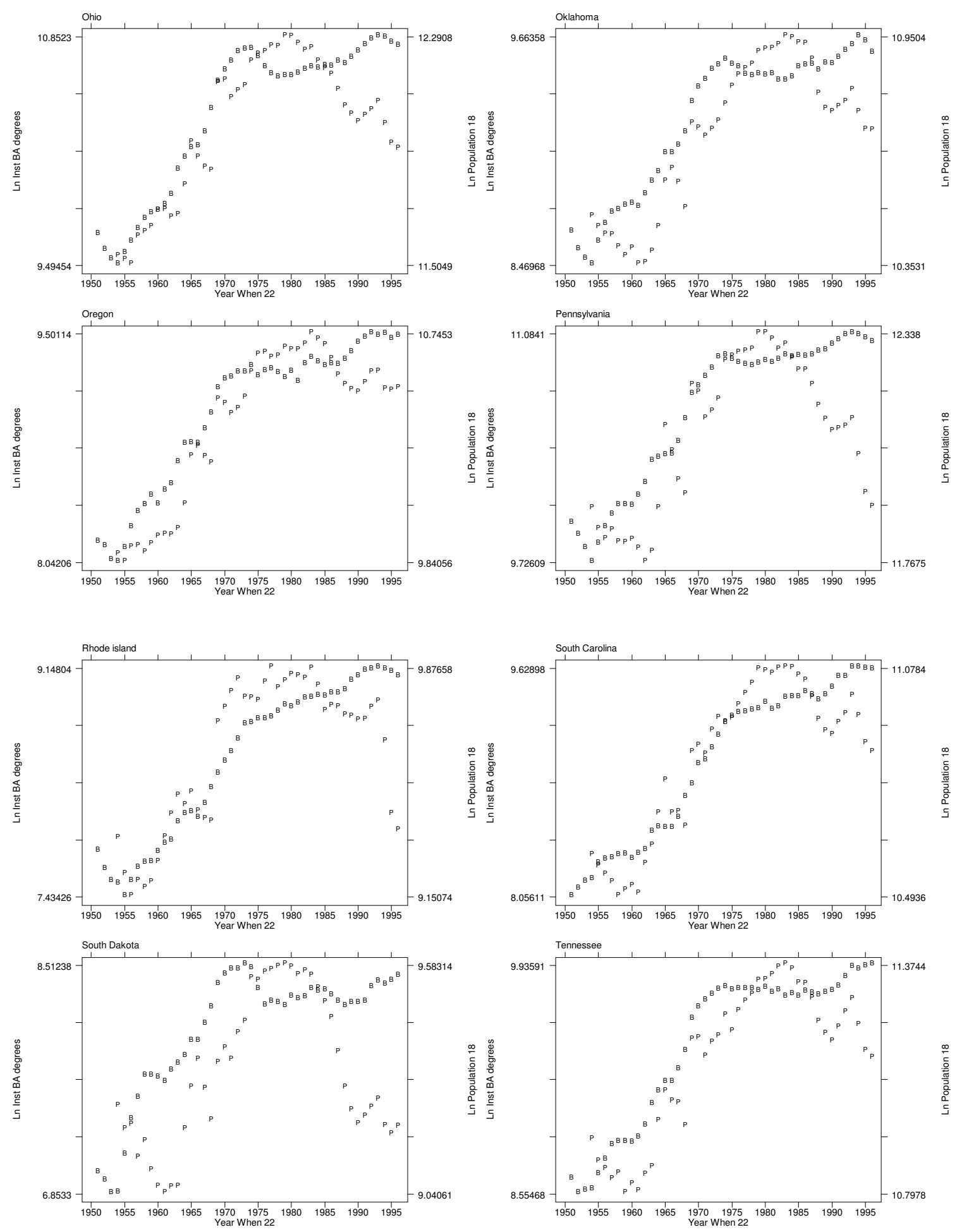

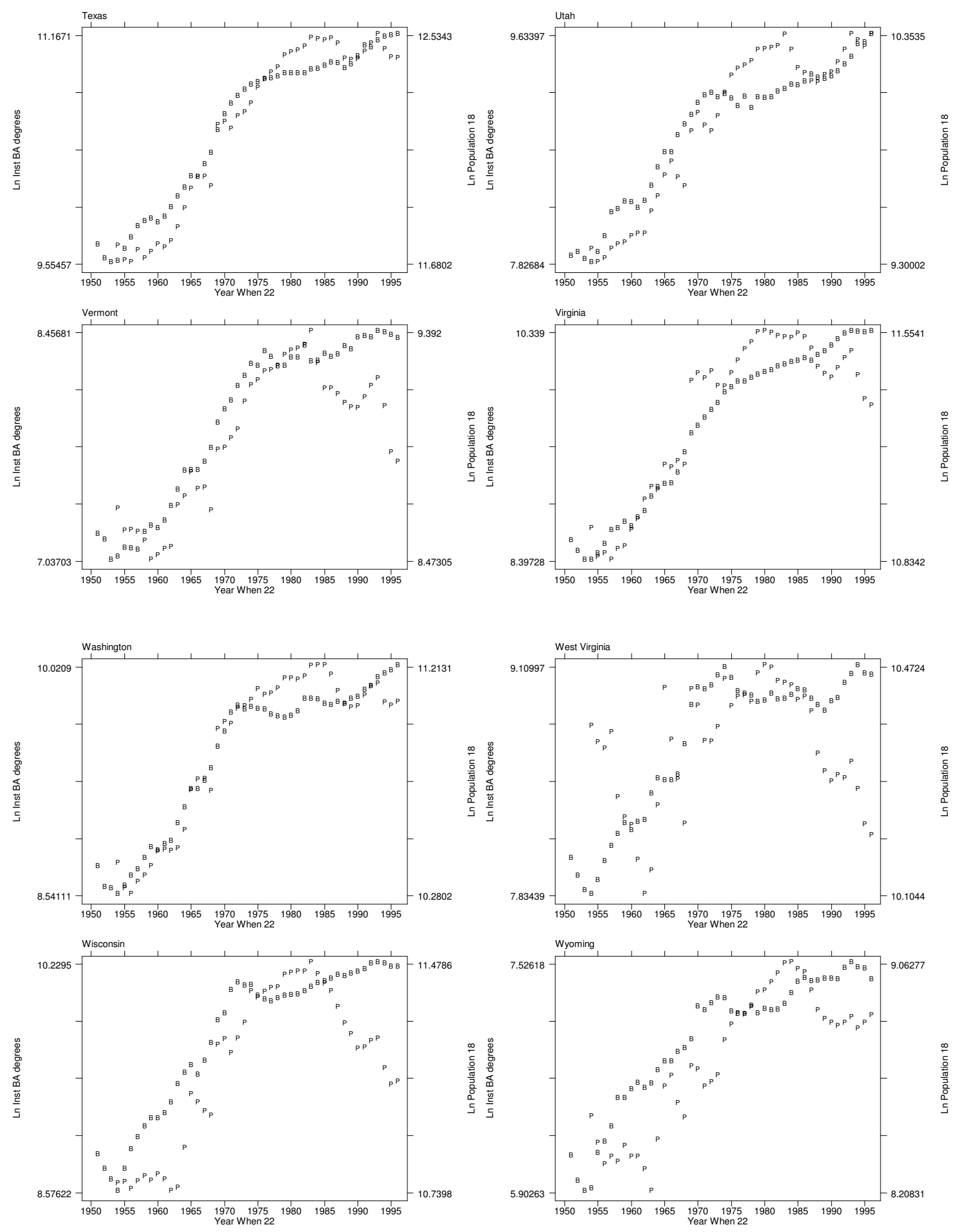